\title{
GAGURITAN DANGHYANG NIRARTHA KAJIAN NILAI-NILAI SOSIAL-RELIGIUS
}

\author{
Ni Nyoman Kertiasih \\ Universitas Warmadewa \\ kertiasih@warmadewa.ac.id
}

\begin{abstract}
ABSTRAK
Tulisan ini merupakan satu kajian terhadap sebuah karya sastra, Gaguritan Danghyang Nirartha (GDN), bersumber dari buku, karya Ida Bagus Putu Bek, dengan judul Kitab Sedjarah Danghyang Nirartha, terbitan Pustaka Balimas, Denpasar, tahun 1961. Karya sastra ini ditulis dalam Bahasa Bali, dalam bentuk tembang (gaguritan), terdiri atas dua tembang (pupuh), yakni: Pupuh Sinom dan Pupuh Durma. GDN menceritakan mengenai perjalanan sejarah tokoh spiritual Hindu, Danghyang Nirartha. Dalam perjalanan itu disinggung terutama mengenai keadaan di Bali, beliau mendapat sambutan baik dari masyarakat (Bek, 1961). Bertemu dengan Bendesa Mas di Desa Mas. Di sana Danghyang Nirartha melaksanakan pembersihan (wisuda) terhadap dua orang menjadi bhagawan (pandita), yakni: I Bendesa Mas dan Kiyayi Dauh Panulisan. Selanjutnya, diundang bertemu raja, Dalem Waturenggong ke istana Gelgel. Beliau mendapat simpati, penghormatan sangat besar, dipercaya menjadi Bhagawanta Kerajaan. Tujuan dari penulisan ini adalah, menggali nilai-nilai sosial religious, sosial kemasyarakatan, nilai-nilai moral yang terdapat di dalam GDN. Dari segi pendekatan, teori, digunakan pendekatan analisis konten dari (Endaswara, 2006). Dalam kajian ini, ditemukan nilai-nilai Agama Hindu, nilai sosial kemasyarakatan, dan nilai moral etika yang berguna bagi kehidupan yang lebih baik di masyarakat.
\end{abstract}

Kata Kunci: Bendesa Mas; Danghyang Nirartha; Waturenggong

\begin{abstract}
This paper is a study about a literary work, Gaguritan Danghyang Nirartha (GDN), which is taken up from the book Sedjarah Danghyang Nirartha, wrote by Ida Bagus Putu Bek, printed by Pustaka Balimas (1961). This literary work is written in Balinese, in the form of a song (tembang). GDN told about a historical event of Danghyang Nirartha, who well known as a spiritualist in the Hindu religion. In about of his historical event, it told particularly when he was in Bali, where he had well come in the society. He met with Bendesa Mas in Mas village, and there Danghyang Nirartha purified two persons who became bhagawan (holy man), namely: I Bendesa Mas and Kiyayi Dauh Panulisan. And then he invited by the King to come to Gelgel palace, met the King of Gelgel. There Danghyang Nirartha got big honor from the King and appointed as a priest (bhagawanta) of the Kingdom. The purpose of this paper is to examine the literary work GDN, by looking at values: social-religious values, sociological, and moral values. In the sense of the theoretical approach, the content analysis model is used in this study, which is taken from Suwardi Endraswara (2003). As a result, in this study can be found some values: Hindu religion values, sociological values, and moral etic values, which are very useful to become better in the living of the society.
\end{abstract}

Keywords: Bendesa Mas; Danghyang Nirartha; Waturenggong

\section{PENDAHULUAN}

Gaguritan Danghyang Nirartha (disingkat GDN) adalah sebuah karya sastra (Bali) dalam bentuk puisi (gaguritan), yang diangkat dari sebuah karya tulis berjudul Kitab Sedjarah
Danghyang Nirartha, karangan Ida Bagus Putu Kebek, terbitan Pustaka Bali Mas, tahun 1961. Penulis (Ida Bagus Putu Bek) menyatakan bahwa Kitab Sedjarah Danghyang Nirartha ini, disusun, disadur dari Babad Danghyang 
Nirartha dengan huruf Latin, berbahasa Bali. Buku Sedjarah Danghyang Nirartha, pada intinya mengungkapkan perjalanan sejarah Danghyang Nirartha dari Jawa (Majapahit) ke Bali, selanjutnya tinggal di Bali, menyebarkan ajaran Agama Hindu. Singkatnya, cerita mengenai sejarah perjalanan tokoh spiritual, Danghyang Nirartha dari Jawa ke Bali, ketika kejayaan Majapahit runtuh terdesak oleh kerajaan-kerajaan Islam yang muncul di kepulauan. Juga menyinggung sekilas mengenai sejarah raja-raja turunan Majapahit di Bali.

Sebagai sebuah karya sastra dalam bentuk buku cetakan, berbahasa Bali, naskah itu beredar luas di masyarakat. Naskah sejarah itu disusun dalam bentuk tembang (gaguritan) yang indah, mudah dimengerti oleh masyarakat. Karena karya berbentuk tembang (gaguritan), maka dalam kajian ini, diangkat judul dengan nama "Gaguritan Danghyang Nirartha" (GDN). Nama "Gaguritan" dimunculkan, mengacu pada bentuk penulisan berupa puisi, "tembang", pupuh, yang banyak digemari di masyarakat Bali. Gaguritan adalah sebuah jenis (genre) dalam kesusastraan Bali yang lumrah terdapat di masyarakat Bali. Disebutkan, gaguritan itu dapat berbentuk terjemahan dari Bahasa yang bukan Bali (seperti Jawa, ke dalam Bahasa Bali, lalu disadur), atau memang berupa karya Bali asli yang berbentuk gaguritan (Agastia, 1980). Menurut Kamus Bali-Indonesia, gaguritan berarti, "saduran cerita yang berbentuk tembang (pupuh) (Bali-Indonesia, 1978).

Selain Kitab Sedjarah Danghyang Nirartha, juga terdapat tulisan sejenis dengan judul Pemargan Danghyang Nirartha, karya I Gusti Bagus Sugriwa, diterbitkan oleh Yayasan Parisada Hindu Dharma Kabupaten Badung, tahun 1975. Juga ada buku karya Soegianto Sastrodiwiryo, berjudul, Perjalanan Danghyang Nirartha (1999), yang menceritakan mengenai perjalanan Danghyang Nirartha selama di Bali. Tetapi buku kedua dan terakhir ini, lebih kental dengan cerita perjalanan Danghyang Nirartha, termasuk penemuan, pembangunan pura-pura yang diprakasai Danghyang Nirartha selama di Bali (Sastrodiwiryo, 1999). Berbeda dengan kedua karya itu, GDN merupakan satu kreativitas, karya sastra dalam bentuk gaguritan (prosa) yang kental dengan nilai-nilai moral, pendidikannya.

Pada dasarnya, Gaguritan Danghyang Nirartha (GDN) selain menceritakan mengenai sejarah perjalanan Danghyang Nirartha dari Jawa ke Bali, juga memberikan gambaran mengenai perjalanan spiritual beliau dalam menjalankan tugas suci mengajarkan agama (Agama Hindu) di Bali. Beliau dipandang sebagai sosok yang memberikan kenyamanan, kesejukan di masyarakat, karena dapat memberikan pengobatan kepada orang-orang yang menderita penyakit (wabah), selain memberikan contoh-contoh baik dalam kehidupan. Selain digambarkan mengenai tempat-tempat yang dikunjungi, Danghyang Nirartha dikagumi kehadirannya sebagai seorang wiku, bagawan yang berwibawa dalam memberikan wejangan rohani kepada masyarakat. Di mana pun beliau datang, selalu dielu-elukan oleh masyarakat yang berharap mendapat anugrah, wejangan, perlindungan dari beliau.

Kehadiran beliau selalu dipandang sebagai kehadiran orang suci, memberi kesejukan, keselamatan bagi masyarakat. Sampai akhirnya, beliau menurunkan putra-putra yang dipercaya sebagai keturunan orang suci, dipercaya masyarakat sebagai guru-guru spiritual, membawa ajaran agama, moral, pendidikan etika bagi masyarakat di Bali.

Oleh karena itu, tampak GDN memiliki nilai-nilai pendidikan, keagamaan yang tinggi, membangun nilai-nilai moral di masyarakat, membawa kemajuan berpikir dalam peradaban manusia yang semakin berkembang. Melihat dari nilai-nilai moral, pendidikan di dalamnya, maka GDN karya Ida Bagus Putu Kebek, menarik dikaji dari sudut nilai-nilai sosialreligius atau moral/etika. Dalam kajian ini, penulis ingin lebih focus pada mengkaji nilainilai social, moral keagamaan (social-religius) yang terkandung di dalamnya. Dengan demikian, diharapkan tulisan ini akan berguna, baik bagi kepentingan kajian karya sastra khususnya, maupun bagi kepentingan masyarakat yang ingin memahami nilai-nilai yang diajarkan guru spiritual Danghyang Nirartha. 


\section{METODE}

Seperti diungkapkan, Gaguritan Danghyang Nirartha (GDN) merupakan karya sastra berbentuk gaguritan, pupuh dan bait-bait pupuh, berbahasa Bali. Dari segi metode, dilakukan pembacaan secara teratur atas GDN, memahami isinya, lalu dibangun suatu synopsis, ringkasan yang jelas tentang isi, temanya. Maka secara teoritis, digunakan pendekatan analisis konten dari Suwardi Endraswara. Dari sinopsis diurai, dianalisis menjadi bagian-bagian dari GDN, sesuai urutan, rangkaian pupuh (isi) yang terdapat di dalamnya.

Dalam hal penyajian analisis, penulisan dibagi ke dalam bab-bab, seperti: Bab I. Pendahuluan, Bab II Sinopsis, Bab III Analisis GDN, yang menguraikan tentang nilai-nilai yang terkandung di dalamnya. Selanjutnya Bab IV Simpulan. Dengan demikian, diharapkan penulisan GDN mengangkat nilai-nilai socialreligius dari karya sastra itu.

\section{PEMBAHASAN}

\section{Sinopsis GDN}

Gaguritan Danghyang Nirartha (GDN) karya Ida Bagus Putu Kebek (1961) terdiri atas 40 halaman, dua pupuh (tembang) yakni: pertama, Pupuh Sinom, terdiri atas 76 bait (hal.1-16), dan kedua, Pupuh Durma, terdiri atas 140 bait (hal.17-40). Mengenai isinya, dapat diringkas sebagai berikut.

Bagian pertama (pupuh Sinom), sebagai awal menulis, penulis menyampaikan maaf yang sebesar-besarnya atas keberaniannya menyampaikan tulisan itu, yang berisi berbagai hal mengenai pengetahuan sejarah, sosial. Terlalu berani menulis dengan pengetahuan yang sangat kurang. Selain itu, apa yang ditulis ini sesungguhnya lebih merupakan cara menghibur diri melihat berbagai kekurangan masyarakat tentang pengetahuan yang perlu dalam bidang sosial keagamaan, dengan memberikan bacaan (pelajaran) yang perlu bagi anak-anak. Di sini juga penulis merendah, sebab dengan segala kekurangannya, ia berani menyampaikan hal-hal penting pengetahuan (tutur) mengenai Bali. Penyampaian merendah dapat dimengerti pupuh berikut.

"Wetu manah titiang girang, milu maguwunin ngawi, manulad sang meraga pradnyan, nanging sangkaning kapidi, antuk anak alit-alit, mangda tityang ngawe kidung, indik Baline satuayang, mamongah titiang mengawi, tuara kimud, wiyakti dados kakedekan" (I.3).

"Nggih sampura rihin tityang, sira ja sudi miragi, tityang nyatuayang sejarah, dening antuk tityang ngoping, menawi yang wenten selip, sampun banget salit kayun, dening indike tuwi katah, wenten irika ring Bali, apan tityang ngeresepang tunayan manah" (I.4).

Artinya (secara bebas):

"Muncul pikiran, ikut belajar menulis, meniru orang-orang pandai, tetapi karena kehendak sendiri, juga desakan anakanak muda supaya saya mengarang kidung, menceritakan tentang Bali, memberanikan diri mengarang, tidak punya malu, biarpun menjadi tertawaan" (I.3).

Selanjutnya, pengarang menceritakan singkat mengenai Danghyang Nirartha ketika di Jawa. Beliau merupakan putra dari Mpu Semara Natha, cucu dari Mpu Tantular, wiku Budha maha suci. Di Daha (Jawa), Danghyang Nirartha mengambil istri bernama Diyah Komala, berputra dua orang. Di sana beliau menganut dua agama, yakni Siwa dan Budha. Juga ketika di Pasuruhan, beliau mengambil istri di sana, berputra empat orang. Juga kemudian mengambil istri di Belambangan, berputra tiga orang, tertua bernama Ida Ayu Swabawa.

Lalu pengarang menyampaikan hal-hal mengenai upcara yang bersifat nista, madya, utama, sesuai petunjuk Ida Brahmana (Pandita). Juga disampaikan jenis-jenis upacara (ada lima), seperti: buta yadnya, upacara ke bawah (mecaru); dewa yadnya, upacara ke Hyang (dewa-dewa); manusa yadnya, upacara ayu, segala upacara manusia; pitra yadnya, upacara mengenai orang mati; dan resi yadnya, sebagai penghormatan kepada Ida Pedanda yang menyelesaikan yadnya (muputang karya). Dalam bagian pertama itu, juga disampaikan mengenai pembangunan pura-pura pemujaan masyarakat yang diprakarsai oleh Ida Danghyang Nirartha, sebagai tempat memuja kebesaran Tuhan (Ida Hyang Widhi Wasa). 
Semua itu penting sebagai kewajiban bagi manusia yang mengerti tata-aturan kehidupan. Ini dipandang penting sesudah kerajaan Bedahulu ditundukkan oleh Patih Gajah Mada, ketika tata krama hilang akibat tiadanya raja yang cakap memerintah di Bali. Untuk membangun Bali secara lebih baik maka dikirim ke Bali seorang raja, wangsa brahmana dari Majapahit, bernama Sri Kresna Kepakisan, yang untuk pertama kali membangun istana di Samprangan (Gianyar). Disebut, beliau mempunyai putra empat orang, yakni: I Dewa Samprangan, I Dewa Tarukan, I Dewa Ketut Ngulesir, dan I Dewa Tegal Besung. Yang terakhir disebut sebagai putra lain ibu yang (penawing) dibanding tiga lainnya.

Disebutkan, keadaan menjadi kurang nyaman ketika kerajaan diperintah oleh I Dewa Samprangan atau dikenal dengan Dalem Ile (putra pertama Sri Kresna Kepakisan), karena raja kurang mampu memerintah. Maka atas inisiatif Kiyayi Kebon Kelapa (Kebon Tubuh), Dalem Ketut Ngulesir dibujuk agar mau menjadi raja dan pusat kerajaan dipindahkan ke Gelgel. Sejak pusat di Gelgel kerajaan menjadi aman di bawah pemerintahan Dalem Ketut Ngulesir. Kerajaan Bali (Gelgel) mencapai keemasannya di zaman Dalem Waturenggong. Di masa pemerintahan Dalem Waturenggong kerajaan Bali mencapai zaman keemasannya. Pada masa itu Ida Danghyang Nirartha datang ke Bali. Beliau menyampaikan banyak petuah, nasehat, pelajaran tentang keagamaan, susila, etika kepada masyarakat. Selain itu, disinggung pula singkat mengenai keadaan kerajaan di Daha (Jawa Timur) pada masa pemerintahan Raja Darmawangsa dan Sri Erlangga, ketika berkembangnya karya sastra oleh para pujangga terkenal. Di zaman pemerintahan Sri Erlangga di Daha, agama Siwa dan Budha dimuliakan. Di masa itu digubah cerita Ramayana dan Bharatayuda. Selanjutnya nyambung ke zaman Majapahit.

Diceritakan pula sekilas tentang keadaan di Gelgel. Disebut pada masa pemerintahan Dalem Waturenggong, kerajaan di Gelgel mencapai masa kebesarannya, dipuja oleh rakyat di Bali. Beliau sangat berpengaruh, karena di zaman itu pula mulai adanya pendeta Siwa dan Budha berfungsi mendampingi raja di Bali, sehingga dikatakan sejak itu ada brahmana di Bali, meniru keadaan di Majapahit.

Bagian kedua (pupuh durma). Bagian ini lebih khusus menceritakan perjalanan Ida Danghyang Nirartha dari Jawa ke Bali. Dari Blambangan, beliau menyeberang Selat Bali menuju Bali, menggambarkan berbagai keajaiban. Dalam pelayaran beliau terpisah dengan putra-putranya. Secara khusus Danghyang Nirartha berlayar tidak menggunakan perahu, jukung biasa, tetapi dengan sarana "daun labu" (waluh kele), yang mengambang didorong angin barat menuju Bali. Sangat mengagumkan. Di pantai Barat Bali, Ida Danghyang turun di pantai Purancak, lalu bertemu orang-orang, yang kemudian menghormatinya. Dibangun pura Rambut Siwi sebagai pertanda penghormatan rakyat kepada beliau.

Dari Purancak beliau menuju desa Gadingwani, juga menemukan orang-orang yang memuja beliau. Di sana di wilayah Gading Wani beliau mengobati masyarakat yang dilanda pandemic (gering) di masyarakat. Mereka dapat disembuhkan, sehingga rakyat sangat hormat kepada beliau. Di sana dibangun pura bernama Pura Melanting Pulaki, sebagai symbol linggih putra beliau yang hilang di hutan, bernama Ida Ayu Swabawa.

Bendesa Gading Wani juga menyarankan Ida Danghyang sudi menghampiri saudaranya, I Bendesa Mas, di Desa Mas (Gianyar). Ia menyatakan ada hubungan saudara, karena dahulu leluhurnya (kumpi) dari Majapahit, bersaudara tiga, yakni: Tan Mundur ditempatkan di sini di Gading Wani, Tan Kober ditempatkan di Desa Mas, menurunkan Bendesa Mas, dan Tan Kawur ditempatkan di Desa Gobleg. Dengan begitu, Ida Danghyang Nirartha datang juga ke Desa Mas, mendapat sambutan sangat baik dari Bendesa Mas. Di sana beliau memberkati (menyucikan) Bendesa Mas dan Kiyayi Dauh Panulisan, menjadi bhagawan.

Dari Desa Mas, lanjut berhubungan dengan Raja Gelgel, dari kehendak raja (Dalem Waturenggong) untuk menjemput beliau di Mas. Ida Danghyang Nirartha merasa senang dan suka datang ke Puri Gelgel. Beliau dijemput oleh Kiyayi Dauh Panulisan. Di dalam perjalanan ke Gelgel, banyak keajaiban terjadi. Semua itu, membuat masyarakat menjadi 
sangat hormat, mengelu-elukan di mana pun beliau datang. Masyarakat Bali, sepertinya terbius dengan kebesaran nama dan kekuatan spiritual beliau dalam mengatasi berbagai kesulitan. Selama di Bali, Ida Danghyang Nirartha menyebarkan kebajikan, pengetahuan tentang agama, prilaku yang baik, menolong orang, dan lain-lain. Banyak hal-hal yang bersifat gaib muncul dari kewibawaan Ida Danghyang Nirartha. Masyarakat Bali memandang beliau sebagai orang suci, guru spiritual, penyebar ajaran Hindu yang membangun Bali masyarakat baru, bertemunya masyarakat Bali Aga dengan kepercayaan aslinya dan penganut Hindu Majapahit, menuju peradaban yang lebih maju.

Sebagai rasa hormat dan kagum, I Bendesa Mas mempersembahkan putri dan seorang pelayan putrinya kepada Danghyang Nirartha untuk ikut dan melayaninya. Kedua putri itu, kemudian dijadikan istri oleh Ida Danghyang, dan masing-masing menurunkan kelompok (soroh) yang dikenal dengan brahmana Mas dan brahmana Petapan. Dengan demikian, muncul 5 kelompok brahmana yang dikenal sebagai keturunan Danghyang Nirartha. Turunan itu adalah: brahmana Keniten, brahmana Kemenuh, brahmana Manuaba, brahmana Mas, dan dan brahmana Petapan.

\section{Analisis Nilai-Nilai GDN}

Pada bagian ini dibahas mengenai nilainilai yang terkadung di dalam GDN, yang sangat besar pengaruhnya pada pengembangan pengetahuan sosial dan keagamaan masyarakat Bali, seperti: nilai agama (Hindu), nilai moral/etika, nilai sosial kemasyarakatan, nilai pendidikan.

\section{Nilai Agama Hindu}

Sebagai seorang $\mathrm{Mpu}$, orang suci, guru tentang ajaran Agama Hindu, Ida Danghyang Nirartha, yang dikenal pula dengan Danghyang Dwijendra, beliau diyakini sebagai orang yang membawa berkah, kesucian. Beliau juga dikenal dengan sebutan, Pedanda Sakti Wawu Rauh, sangat kental dengan pengetahuan yang mendalam mengenai filosofi, ajaran Hindu juga memahami ajaran agama yang lain. Karena merasa terdesak di Jawa, tampaknya beliau harus pergi ke Bali untuk mempertahankan keyakinannya pada Agama Hindu dan menyebarkan ajaran itu pada masyarakat Bali. Masyarakat Bali sangat merasakan mengenai hal itu, dan sampai sekarang memuliakan bangunan-bangunan suci yang diprakarsai beliau, tersebar di seluruh Bali. Beliau pula yang menurunkan golongan (trah) brahmana yang merupakan cakal bakal warga brahmana (pedanda) di Bali.

Berkenaan dengan ajaran agama, Ida Danghyang Nirartha mengajarkan tentang melaksanakan upacara (yadnya) yang wajib dilakukan oleh penganut Agama Hindu. Ada lima jenis yadnya yang disampaikan, yang disebut Panca Yadnya. Dalam GDN disebutkan:

"Dening Ida Sang Pandita manados keretaning bumi, ngalugraha sang nguwangun yadnya, lelima yadnyane sami, manggeh memargi ring Bali. Muta yadnya karya macaru, Dewa yadnya karya ring Hyang, Manusa yadnyane malih, karya ayu saluwir mahayu manusa" (I.10).

Artinya (secara bebas):

Karena beliau Pendeta menjadi peneduh bumi, memberikan izin orang yang melaksanakan upacara (yadnya). Ada lima jenis yadnya yang wajib dilaksanakan. Butayadnya, yadnya untuk makhluk bawah (mecaru). Dewayadnya karya untuk Hyang (dewata). Dan manusayadnya, adalah karya suci untuk kepentingan manusia (I.10).

"Mitra yadnyane kaucap, karya ngardinin sang mati. Punika yadnyane patpat, awinan lelima sami, resi yadnya manulurin, salwiring yadnya kawangun maduluran resi yadnya, jauman daksina suci, punia katur ring Peranda mupoutang karya" (I.11).

Artinya (secara bebas):

Disebutkan mengenai pitra yadnya, adalah upacara mengenai orang mati. Itu yadnya yang keempat. Menjadi lima dengan resi yadnya. Setiap melaksanakan yadnya patut diikuti resi yadnya, berupa sajian daksina suci, selaku persembahan dihaturkan kepada Pedanda yang menyelesaikan (muput) karya (I.11). 
Tidak hanya mengenai jenis upacara (yadnya) yang disampaikan, tetapi juga mengenai filosofi (tatwa) menjalankan ajaran agama. Disebutkan, bahwa cerita demikian tercantum dalam buku-buku agama (adigama, purwa agama, sarasamuscaya) dan lain-lain. Buku-buku itu menuntun masyarakat untuk memahami ajaran agama, dengan cara penggambaran peristiwa dalam bentuk "purana", cerita berbau mitologis yang mudah dimengerti. Seperti disebutkan antara lain.

"Malih pawangun Sang Pandita, indik amahayu bumi, agama lan adigama, purwa adigama nyarengin, Utara Manawa malih, Dewa Tatwa muah Sua Yambu, Sarasamuscaya Agama, gelar sang mangeraksa bumi, kamargayang antuk sang kreta diksita" (I.34).

Artinya (secara bebas):

Ada juga ajaran Sang Pandita tentang penyucian bumi, tercantum dalam lontar Agama, Adigama, Purwa Adigama, Kutara Manawa, Dewa Tatwa, Sua Yambu, Sarasamuscaya, semua cerita tentang agama, sebagai kewajiban bagi para pemegang kekuasaan, dijalankan oleh sang bagawanta (I.34).

Beliau juga memperkenalkan agama Siwa dan Buda sebagai agama yang pantas dianut, dalam konsep Rwa-bhineda, dua sisi yang saling melengkapi, menjadi pedoman hidup di dunia.

"Awinan Danghyang Nirartha ngambil agama kekalih, Siwa Budha linaksanan, maggeh manyuda seridanti, nyawa wedana innipti, maka ruwa tuah kaginung, apan ida sampun wasman ring indik tatuannya sami, meawinan, Ida meparab Dwijendra (I.71).

Artinya (secara bebas):

Disebut, Ida Danghyang Nirartha menganut dua agama, Siwa dan Budha. Itu dugunakan untuk menyucikan dalam upacara pembersihan orang mati, kedua agama itu dijalankan, karena beliau sudah mengerti betul filosofisnya. Karena itu, beliau diberi nama, Dwijendra (I.71).

Di awal kedatangan Danghyang Nirartha di Bali, beliau juga tidak membedakan keturunan (soroh) tertentu saja yang boleh menyandang status sebagai bagawan (orang yang disucikan). Beliau, sebagai guru agama, guru spiritual Hindu, memahami, bahwa setiap orang, tidak membedakan, siapapun yang bersungguhsungguh, dapat menjalankan kehidupan sebagai orang suci, rohaniawan (tokoh agama, brahmana). Hal itu ditunjuukkan dengan diwisudanya I Bendesa Mas menjadi bhagawan oleh Danghyang Nirartha. Dalam GDN diungkapkan sebagai berikut.

"Bendesa Mas mepes matur manyumbah, tituang ndaweg matur sisip, presangga mapinunas, pangeleburan malan tityang, ring dewek tityang ngebekin, suwecanin mangeruwat, mangda sida ugi beresih" (II.68).

Artinya (secara bebas):

Bendesa Mas dengan hormat menyampaikan, hamba mohon maaf menyampaikan, memberanikan diri memohon pembersihan diri, karena kekotoran memenuhi diri hamba, berkati pembersihkan agar bisa menjadi bersih (II.68).

"Danghyang Wawu Rauh alon ida ngandika, nah bapa nugerahin cai, ne jani apang madiksa, Bendesa Mas ngiringang, manguntuk nikel mebakti, sampun wus mapodgala, saha upakara sami" (II.70).

Artinya (secara bebas):

Danghhyang Wawu Rauh, berbicara pelan, nah bapa memberkati engkau, sekarang dibersihkan (mediksa). Bendesa Mas mengikuti, dengan tunduk khusuk berbakti, setelah itu semua upacara penyucian (mapodgala) selesai.

Tidak hanya kepada Bendesa Mas, tetapi juga kepada Kiyayi Dauh Penulisan (pendamping Dalem di Gelgel), diberikan kesempatan untuk menjadi bhagawan, orang yang disucikan. Itu juga karena kehendak sendiri yang kuat untuk menjalankan tugas kependetaan. Ida Danghyang Nirartha tampak memahami semangat orang yang bersungguhsungguh untuk belajar kerohanian (agama). Ketika Kiyayi Dauh Panulisan menghadap Danghyang Nirartha di Desa Mas, terjadi diskusi pembelajaran tentang agama. 
"Meneng Kiyayi Dauh Panulisan, mangerasa-rasa ring hati, sampun presida karasa, bawose sang Pandita, Kiyayi Dauh matur malih, inggih punapi tatuanya, wilanganing windu jati" (II.95).

Artinya (bebas):

Kiyayi Dauh Panulisan, terdiam, merasarasa dalam hati, sudah dimengerti wacana Sang Pandita, lalu Kiyayi Dauh Panulisan berkata lagi, ya bagaimana pengertian tentang 'bilangan windu jati'? (II.95), menunjukkan kesungguhan Kiyayi Dauh Panulisan untuk belajar kerohanian.

"Inggih suwecanin tityang, wantah nuhun pada, manyadia pacang nyiwi, wiyakti buk padan Danghyang, saking jati nirmala, mapinunas mabersih, nunas pangelukatan, pangeruwat malaning dadi" (II.99).

Artinya (bebas):

Ya berkatilah hamba, mohon sedekah, siap akan mengabdi kepada Paduka Yang Luhur (Danghyang), atas dasar pikiran yang jernih, mohon dibersihkan, memohon air pembersihan, pembasmi segala kekotoran (II.99).

"Danghyang Wawu Rau alon mawacana, bapa jani nyawecanin, atur Kiyayi Panulisan, jani mapodgala, Bendesa matur bakti, inggih yan upakara, tityang ngaturang sami" (II.100).

Artinya (bebas):

Danghyang Wawu Rauh berbicara pelan, bapa sekarang memberkati, lalu menjawab Kiyayi Penulisan, sekarang dibersihkan (mapodgala). Bendesa Mas menyambut hormat, mengenai keperluan upakara, saya yang menyiapkan semua ((II.100).

\section{Nilai Sosial Kemasyarakatan}

Sebagai nilai-nilai sosial kemasyarakatan dapat dimengerti dalam hubungannya dengan sikap, tingkah laku yang baik, sejalan dengan rasa kepatutan masyarakat, tradisi, aturan sosial (awig-awig) yang dibangun bersama di dalam masyarakat. Hal itu dipandang penting dalam membentuk karakter manusia menjadi mengerti aturan, mana yang pantas dan mana yang tidak pantas. Dalam hubungan itu, GDN memberikan arah nilai menuju pemahaman yang maju menuntun sikap prilaku manusia bermasyarakat, sebagai berikut.

"Malih wenten kacarita, desa dresta lingging aji, saking sukan I wong desa, ngawit nguwangun awig-awig, ne patut pacang marginin, kemanggehang mange tunggul, kemargiang ketetepang, rawuh kewekas ketami, dening desa, dening dresta tui wastannya" (I.45).

Artinya (secara bebas):

Ada lagi diceritakan, yang ditulis sebagai 'desa dresta', atas kehendak warga desa membuat aturan (awig-awig), yang pantas dijalani, dipelihara sebagai tunggul, dijalankan terus, sampai dikemudian hari, itu disebut sebagai desa dresta (I.45).

"Purwa drestane kaucap, pematute saking rihin, sesanane kemanggehang, nurut salingging aji, wong desane menganutin, purwa dresta wastan ipun, niti suarane kacerita, perarem sang merentah gumi, ngawit nguwangun, wet pakertaning jagat" (I.46).

Artinya (secara bebas):

Disebutkan, ada tradisi, kepatutan sejak dahulu, prilaku baik dikukuhkan, mengikuti ucap sastra, orang desa mengikuti, itu disebut 'purwa dresta'. Ada juga 'pedoman tertulis' (niti suara), sebagai kepatutan sang pemegang kekuasaan, membangun keajegan jagat (I.46).

Semua itu menunjukkan betapa berbagai kesepakatan dan kewajiban diperhatikan agar dapat menjadi patokan, pedoman hidup bermasyarakat. Hidup rukun di masyarakat, perlu memperhatikan berbagai ketentuan, peraturan yang dibuat untuk membangun ketertiban masyarakat.

\section{Nilai Pendidikan Moral, Etika}

Nilai Pendidikan moral, etika dimaksudkan untuk memahami adanya nilai kebaikan, kearifan, sikap moral dan etik, yang dianjurkan, 
terdapat di dalam GDN. Nilai-nilai ini tidak lepas dari arah yang diberikan dalam kaitan dengan agama, agar dapat berbuat sepantasnya, tidak bertentangan dengan nilai-nilai keagamaan. Dalam hubungan itu, konsep Rta (hutang budi) dan hukum karma, memberi landasan pada sikap etik dan moral, memberi arah pada perbuatan, mana baik dan mana yang tidak baik. Agama Hindu memperhatikan landasan kebaikan itu (Suamba, 2003: 214).

Di sini dapat disampaikan sebagai berikut. "Malih jagra mangulatang, nganutang sakadi indik, ling Hyang agama sasana, anggen Ida mituturin, tingkahe awinan sisip, tan wenang ngerabinin ibu, wiadin pianak keponakan, nyama uwa bibi, tumin, nucap iwang, mewasta lembu akulah" (I.36).

Artinya (bebas):

Juga sanggup menjalankan kewajiban mengikuti aturan agama, tingkah laku dijadikan teladan, yang menyebabkan salah, diberikan petunjuk, adalah: tidak boleh bersenggama dengan ibu, juga dengan anak keponakan, saudara paman/bibi, ibu tiri, itu yang disebut lembu akulah (I.36).

"Malih yang kereng mautang, dulurin demen mangutil, payu ban nyongah mamegal, wong desa ngulah tui sengit, mewasta kidang tawan kanin, reh sampun metanda dudu, yan melaksana melegandang, amurugul bawud anggeris, wiyakti iwang, mewasta celeng bolotan" (I.37).

Artinya (secara bebas):

Juga bagi yang kuat berhutang, karena mengikuti hasrat menguasai milik orang lain, hidup dengan prilaku begal, menyebabkan orang desa mengusirnya karena marah, orang seperti itu, disebut 'kidang tawan kanin', karena sudah berbekas curang. Jika berbuat memperkosa, memaksa dengan segala cara, tentu salah, disebut, 'celeng bolotan' (I.37).

Disampaikan pula, "Wenten dusta ngetut anak, reh liyu mengaba pipis, kematiang ring jalan sunia, barangnya sami keambil, $i$ dusta raris melaib, wenten anak len rauh, mandeg, bengong ia ngantenang, katur ring sang ngeraksa bumi, kabawosang, 'mengadeging penganggasan" (I.40).

Artinya (secara bebas):

Ada orang pendusta membuntuti orang lain, karena membawa banyak uang, lalu dibunuh di tempat sepi, semua barangnya diambil, orang dusta itu lari, lalu diketahui oleh orang lain yang datang, lalu diam, bengong melihatnya, selanjutnya dilaporkan kepada pihak berwewenang, diperkarakan, itu disebut, 'pengadeging penganggasan' (I.40).

Selanjutnya, ada juga perbuatan cela, disebut sadtatayi, yakni enam macam perbuatan yang dilarang oleh etika di dalam masyarakat. Di dalam GDN dinyatakan:

"Yan sadtatayi tatuanya, neluh wisesa nyakitin, ngupas, nuba ngawe rusak, ngamuk ruwang dadi mati, nunjel umah wiyakti basmi, memaksa istri murugul, malih ngeraja pisuna, ento madan sadtatayi, tan dadi ampun, sisipnyane wiyakti berat" (I.42).

Artinya (secara bebas):

Ada lagi cerita tentang, saddtatayi, keburukan yang enam jumlahnya, yakni: (1) menyakiti dengan black magic, (2) meracun membuat orang sakit, (3) mengamuk orang sampai mati (4) membakar rumah, (5) memaksa istri orang, (6) membuat fitnah. Itu tidak bisa diampuni, kesalahannya sangat berat (I.42).

Masyarakat juga bersikap hormat, etis kepada Ida Danghyang Nirartha yang banyak berbuat dan dikagumi dalam mengatasi berbagai permasalahan di masyarakat, seperti yang ditunjukkan di Desa Gading Wani, Jembrana, ketika pada awalnya beliau tiba di sana, seperti menyembuhkan masyarakat dari wabah penyakit yang menyerangnya. Seperti diungkapkan.

"I Wong desa sami pada mangawokang, I Bendesa tui mamuji kasidiyan kayun Danghyang, kadi dewa nyalantara, wiyakti tan patanding, I wong desa, makejang boya wenten kari sakit (II.35). 
Artinya (bebas):

Masyarakat desa semua mengagumi, I Bendesa memuji keampuhan, ketajaman pikiran, Danghyang Nirartha, diandaikan sebagai dewa, malaikat turun, benarbenar tidak tertandingi, karena tidak ada lagi warga desa yang sakit (II.35).

Sebagai prilaku etis, membalas jasa, warga sewilayah desa Gading Wani merasa perlu mempersembahkan sesuatu kehadapan Ida Danghyang, juga pengormatan untuk memuja arwah putri beliau yang bernama Ida Ayu Swabawa, yang menghilang di hutan desa itu.

"I wong desa luh muani pada girang, sakuwubin Gading Wani, memanah pacang maturan sawentenne ring desa, woh-wohane manis-manis, mekadi rayunan, ulamnyane sarwa suci" (II.36). Artinya (bebas):

Warga desa, laki-perempuan di wilayah Gading Wani, berkehendak mempersembahkan sesuatu seadanya, seperti: buah-buahan, makanan, daging yang serba suci (II.36).

"Iyanak Betari Swabawa linggihang iriki ring Melanting Pulaki, Ida sungsung tityang sareng wong desa sinamiyan sakuwuban Gading Wani, Danghyang ida miarsa, raris Ida nyaurin" (II.46).

Artinya (bebas):

Putri, betari Ida Ayu Swabawa mohon untuk dilinggihkan (buatkan pura) di sana di Melanting Pulaki, ida akan disungsung oleh seluruh masyarakat Gading Wani, dan Danghyang Nirartha menyetujuinya (II.46).

Penerimaan sangat hormat dan meriah juga diterima ketika beliau datang di Desa Mas, Gianyar. Kunjungan ke desa Mas disambut sangat ramah oleh masyarakat.

"Tana suwe rawuh suamine Bendesa, wiyakti tangkepe pangid, sebenge tama elah, praya ngaturang rayunan, panjeroane katah ngiring, sami masuhunan dabdab, nunas lugera raris tangkil" (II.65).

Artinya (bebas):
Tidak lama ketika sampai di Gading Wani, datang I Bendesa Gading Wani, sikapnya pantas, hormat, santai, sudah siap mau menghaturkan makanan, diiring oleh banyak pelayan, semua menjunjung barang rapi, memohon dengan hormat, menghadap (II.65).

Lebih jauh disebutkan, karena saking hormat dan menghargainya, seperti telah disinggung di atas, I Bendesa Mas sampai mempersembahkan putri dan seorang pelayan putrinya, agar diajak oleh Danghyang Nirartha, untuk melayani. Kedua putri itu, kemudian dijadikan istri pula oleh Danghyang Nirartha, menurunkan Brahmana Mas dan Brahmana Petapan. Disebutkan dalam GDN.

"Bendesa Mas raris ipun mangaturang piyanaknyane istri, maka panguriyaga, maduluran panjerowan, punika makakalih kaambil antuk Danghyang, kasuwen maputra kalih" (II.76).

Artinya (bebas):

I Bendesa Mas lalu mempersembahkan putrinya sebagai hadiah khusus (penghormatan), disertai seorang pelayan (pembantu), dan kemudian keduanya dijadikan istri, lalu masingmasing memiliki putra (II.76).

"Anak Bendesa Mas muterayang Ida Watek Mas, anak panjeroane malih ngawentenang Ida Petapan, kalokayang Mas Alitan, putran Danghyang Wawu Prapta, kang wijiling Jawa, tembenin malih midarti" (II.77).

Artinya (bebas):

Anak Bendesa Mas berputra, disebut Ida Watek Mas, dan anak pembantunya berputra, disebut Ida Petapan, atau Mas Alitan. Ada pula putra-putra Danghyang Nirartha yang lahir di Jawa (II.77).

Dengan pemaparan di atas, cukup memberikan pemahaman mengenai betapa GDN memiliki nilai-nilai pendidikan yang berguna bagi kehidupan masyarakat, menuntun masyarakat baik mengenai keagamaan, sjstem kemasyarakatan, dan tata krama, nilai etika moral di masyarakat. Nilai-nilai itu, sampai kini menjadi pedoman, penuntun masyarakat Bali dalam bertingkah laku di masyarakat, menjadi 
bagian dari nilai-nilai budaya Bali secara keseluruhan.

\section{SIMPULAN}

Dengan uraian singkat di atas dapat disampaikan, bahwa Gaguritan Danghyang Nirartha (GDN) pada dasarnya adalah sebuah karya sastra berbentuk tembang (gaguritan), bercerita tentang sejarah perjalanan dan keadaan hidup Danghyang Nirartha sejak berada di Jawa sampai ke Bali. GDN bercerita tentang keadaan Danghyang Nirartha ketika berada di Daha, Pasuruhan, Blambangan dan mengambil istri di sana, dan semua putraputranya kemudian diajak ke Bali. Di Bali, beliau bertemu dengan masyarakat desa di Pantai Purancak, masyarakat Gading Wani yang mengaguminya, sampai dibangun pura Rambut Siwi dan Melanting Pulaki. Di Desa Mas, Danghyang Nirartha mewisuda, menyucikan dua orang menjadi bhagawan yakni: I Bendesa Mas dan Kiyayi Dauh Panulisan. Diundang oleh Dalem Waturwenggong, kemudian tinggal di sana, menjadi purohita kerajaan. Ketika kerajaan didampingi oleh pandita Danghyang Nirartha sebagai bhagawanta kerajaan, kerajaan mencapai zaman keemasannya, besar pengaruh dan kekuasaannya.

Di Bali Danghyang Nirartha mewariskan putra-putranya, menjadi cakal bakal golongan brahmana, yang penting peranannya sebagai guru spiritual, penyebar agama, membawa trah brahmana dari Majapahit. Atas kehadiran Danghyang Nirartha, Bali menjadi muncul, maju dalam peradaban, bertemunya unsurunsur kepercayaan Bali Aga dan keyakinan Agama Hindu sebagai inti, roh kebudayaannya.

Sesuai dengan tujuan dari penulisan ini, menggali nilai-nilai di dalamnya, maka dapat disimpulkan, bahwa nilai-nilai yang terkandung di dalam GDN, sebagai berikut. (1) Nilai sosial- religius, seperti tercermin dalam ajaran yang disampaikan, yakni: keyakinan kepada ajaran kesucian, terkandung di dalam kitab-kitab suci (agama, adi agama, purwa agama, sarasamuscaya, purana, dan lain-lain). Dalam kaitan itu dijabarkan pelaksanaannya dalam bentuk upacara pancayadnya. (2) Nilai sosial kemasyarakatan, seperti: mengerti tata krama, mengikuti aturan-aturan yang dibuat (awigawig), juga mengerti dengan aturan yang dibuat oleh raja, penguasa yang disebut Niti Suara. (3) Nilai moral, etika, dijabarkan seperti: mengerti tata perbuatan yang dipandang baik dan buruk. Perlu memahami perbuatan yang disebut "sadtatyi", enam jenis perbuatan yang tidak baik (dilarang) dilakukan.

Demikian, berbagai nilai, sikap baik dan buruk dijabarkan, muncul dalam GDN, dapat memberi pendidikan, menjadi pedoman untuk kehidupan yang lebih baik.

\section{DAFTAR PUSTAKA}

Agastia, I. B. G. (1980). Geguritan Sebuah Karya Sastra Bali.

Bali-Indonesia, P. P. K. (1978). Kamus BaliIndonesia. Dinas Pengajaran Propinsi Daerah Tingkat I Bali.

Bek, I. B. P. (1961). Kitab Sedjarah Danghyang Nirartha. Pustaka Balimas.

Endaswara, S. (2006). Metode penelitian sastra. Gadjah Mada University Press.

Koentjaraningrat. (1974). Kebudayaan, Mentalitet dan Pembangunan. PT Gramedia.

Sastrodiwiryo, S. (1999). Perjalanan Danghyang Nirartha. Penerbit Bali Post.

Suamba, I. B. P. (2003). Dasar-dasar Filsafat India. Program Magister Ilmu Agama dan Kebudayaan Universitas Hindu Indonesia. Bekerjasama dengan Penerbit Widya Dharma. 